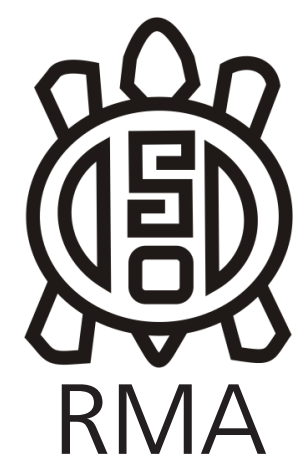

Dossier

\title{
Dossier: Conociendo a Marit Melhuus
}

\section{Entre la política y la academia: una tesis sobre productores tabacaleros}

Jorun Solheim

Institute for Social Research. Oslo. E-mail jorun.solheim@samfunnsforskning.no

Querida Marit:Trataré de presentar una imagen de tus primeros años en la Universidad de Oslo, principalmente en lo concerniente a tu tesis de Magistergrad ${ }^{1}$ en Antropología Social, que presentaste en 1978. No recuerdo exactamente cuándo fue que te encontré por primera vez, pero debió ser varios años antes, probablemente a principios de los 1970s. En ese entonces me acababan de tomar como University Lecturer en el Departamento, y tú acababas de regresar después de varios años en el exterior y habías empezado tus estudios en Antropología Social. No me acuerdo en qué momento de la Carrera estabas cuando nos conocimos, y si ya habías empezado tus estudios de posgrado. Esto se me fue por completo, probablemente porque fue en los 70s, una época oportuna para el compromiso político profundo y para la crítica del programa tradicional y de los cursos del Departamento. Era un tiempo en que los estudios y la política y la sociabilidad general estaban estrechamente unidas, y nosotros, que por aquella época pertenecíamos a la extrema izquierda, pasábamos el tiempo en continuos debates acerca de absolutamente todo, y el tema de quién se recibía cuándo y con qué exámenes eran cuestiones totalmente subordinadas a todas esas cosas que nos involucraban.

Lo que sí recuerdo es que en algún momento nos hicimos amigas. Quizás, fue en el medio de una discusión sobre André Gunder Frank y la teoría de la dependencia económica. O fue en otra discusión acerca de la definición de "campesinado" que daba Eric Wolf. O sobre la antropología marxista en general-en qué medida y cómo era posible usar la teoría marxista para entender sociedades no-capitalistas. ¿No fue acaso en tu cabaña en Tromøya que tuvimos ese seminario increíblemente emocionante que se extendió por varios días, donde nos sumergimos en la introducción de Marx a los Grundrisse, "Formas que preceden a la producción capitalista"? Porque eran esas cosas las que nos interesaban en aquella época, y la primera cuestión era comprender cómo interactuaba el capitalismo global con formas precapitalistas de producción, bajo qué formas y lógicas tenía lugar esta interacción, y cómo esto influía en el desarrollo económico en eso que, por entonces, se llamaba Tercer

\footnotetext{
${ }^{1}$ El magistergrad era un grado que había en la Universidad de Noruega, ubicado entre el Doctor Philosophiae y el Master. Luego fue reemplazado por el Ph.D.
}

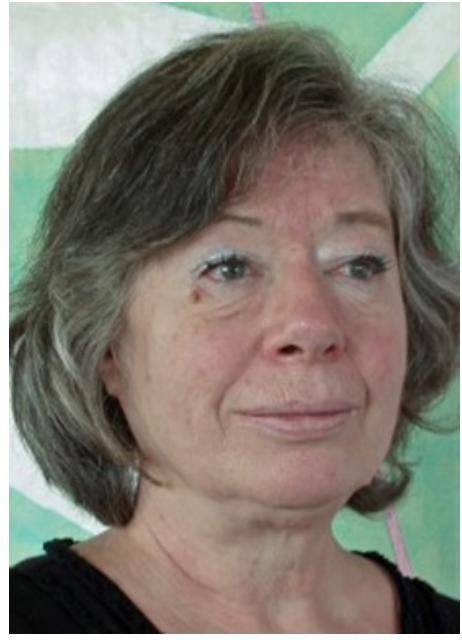

Figura 1: Jorun Solheim. (Foto: Kristin Engh Førde)

Figure 1: Jorun Solheim. (Photo: Kristin Engh Førde)

Mundo. Nuestra amistad estaba, desde el comienzo, metida en estas discusiones. Nos encontrábamos como profesionales e intelectuales aliadas, apasionadamente comprometidas en los mismos problemas generales. Gradualmente, nos empezamos a ver también en un nivel más íntimo y personal. O quizás todo esto sucedió al mismo tiempo.

Luego te fuiste a Corrientes, al campo argentino, para estudiar la economía doméstica y la integración de mercado de un grupo de productores de tabaco. Era un trabajo de campo situado justo en el medio de las problemáticas que he mencionado, llamado en aquel momento "estudios campesinos". Los campesinos que, en palabras de Eric Wolf, "llevan un hogar, no una empresa" y que, por lo tanto, no siguen una lógica de producción capitalista con la maximización de ganancias como objetivo, sino que simplemente luchan por sobrevivir. Y, por lo tanto, pueden ser explotados de muchas maneras, tanto abiertamente como de modos más ocultos. Fue esto lo que se convirtió en el problema general de tu tesis de maestría: revelar esta lógica de explotación a través del estudio de un caso específico, a saber, los campesinos productores de tabaco en la estancia San Antonio, en la provincia de Corrientes. 
Me convertí en tu tutora cuando volviste del trabajo de campo. Y recuerdo nuestras interminables discusiones, cómo ambas nos enterrábamos en tu enorme material de campo, cómo luchaste para dar sentido a tu increíblemente detallada masa de datos y gradualmente desarrollaste tu argumento sobre cómo "tus" campesinos creaban un excedente económico que era expropiado por otros. O, en tu propia formulación: "el problema no es que los campesinos no puedan producir un excedente, sino que no puedan apropiárselo, pues se lo queda el terrateniente.

La tesis se llamó Campesinos, excedentes y apropiación. Un análisis de la integración estructural de los productores de tabaco de Corrientes. Cuando la releo hoy, casi 40 años después, me llaman la atención dos cosas en particular. Una es el trabajo de campo extremadamente minucioso y detallado que hiciste, y cuán extenso es el análisis. Nos das una visión histórica de la estructura de la propiedad en toda la provincia de Corrientes, haces una presentación de los diferentes tipos de propietarios de tierras, de pequeños y grandes productores, y en qué tipo de relaciones de producción y estructuras de mercado están involucrados. Escribes sobre las relaciones patrono-cliente, sobre integración social, divisiones y conflictos. Escribes sobre diferentes tipos de suelo, describes las distintas etapas de la producción de tabaco, analizas la composición y las estrategias de los hogares en diferentes períodos del ciclo de desarrollo del hogar, centrándote en la relación entre la fuerza de trabajo, la tecnología y los recursos. Por último, pero no por eso menos importante, haces un cálculo minucioso y detallado del costo de producción de los hogares, en relación con el precio que obtenían por su producto, en un intento de estimar el excedente que estos campesinos realmente producían. Un trabajo formidable.

La otra cosa que me sorprende es lo atrevida y original que eras. Sólo por este último punto, la estimación del excedente representaba un problema principal, de hecho, el problema principal de tu tesis. $Y$ de ninguna manera era fácil de resolver. Porque tus campesinos producían, en tu opinión, un doble excedente. Por un lado, eran inquilinos, aparceros, obligados a renunciar a parte de su cosecha, en beneficio del propietario. Este excedente era visible y fácil de demostrar. Pero tú querías demostrar que también producían un excedente "invisible" que era expropiado a través del mecanismo del mercado, al vender su producto a las grandes compañías tabacaleras a un precio que no cubría sus costos reales de producción. Sin embargo, el problema de mostrar esto era que no había forma de estimar el valor del trabajo real que se dedicaba a la producción, ya que los campesinos no consideran su propia mano de obra como un factor de costo. No tiene un valor económico evidente, no tiene precio.

Tu solución a este problema, y recuerdo que esto te causó mucho trabajo intelectual, fue hacer un cálculo en el que estipulabas cuáles hubieran sido los costos de producción de los campesinos si hubieran sido productores capitalistas, y hubieran pagado un salario mínimo por la mano de obra aplicada a la producción. Estos costos, que eran posibles de calcular, resultaron ser mucho mayores que el precio que los campesinos realmente obtenían por su tabaco. En otras palabras, al comprarle al campesinado sin tierra, las compañías tabacaleras podían pagar un precio mucho más bajo de lo que hubieran tenido que pagar si le hubieran comprado a productores capitalistas. Según lo veías, esta invisible "ganancia extra" era una explicación importante de por qué una economía campesina podía coexistir y subsumirse en el marco de una economía capitalista. Era extremadamente rentable para la industria tabacalera.

Y esto es lo que veo hoy como tu audacia y originalidad creativa: que te atrevieras a sacar estas grandes conclusiones, que tratas de mostrar las implicaciones generales de tu caso local, a pesar de que no pudiste probar directamente la existencia de este excedente invisible. No pudiste hacerlo, sólo señalarlo, hacerlo plausible de manera indirecta. Y así lo hiciste. Cuando me siento hoy a mirar tus complicados cálculos, debo decir que son bastante convincentes. Es probable que el análisis no cumpla completamente con la teoría del valor de Marx, que era tu criterio en aquel entonces; puede ser, por ejemplo, que lo que sigue siendo problemático sea algo acerca del valor de la fuerza de trabajo contra el valor del trabajo. Pero no importa: el argumento principal sigue vigente. $Y$, debo agregar, la teoría del valor del trabajo de Marx tampoco está exenta de problemas.

Pienso que es esta audacia, tu deseo de seguir un argumento hasta el final para ver adónde te lleva, tu aproximación no-ortodoxa hacia un problema -porque aún en tu período marxista eras bastante poco ortodoxa-, tu rica y creativa imaginación combinada con un estudio empírico detallado, que fueron tu marca distintiva a través de toda tu carrera académica. Tal fue el caso de tu trabajo doctoral en México, que empezó también, si no recuerdo mal, como un análisis económico y terminó como un estudio de género y religión, centrado en torno a la devoción a la Virgen de Guadalupe. Porque el campo te llevó ahí! (énfasis original).

Pero ésta es otra historia. Te dejé allí, en 1978, en tu camino hacia tu primer trabajo académico en $\mathrm{AFI}$, adonde te seguiría algunos años más tarde. Pero suelo pensar que fue el trabajo de campo en Corrientes lo que te hizo antropóloga y académica. Por eso es tan adecuado que hayas vuelto allá. Lo que salga de allí, lo dirá el tiempo.

Salud Marit, amiga, colega y "socia en el crimen" intelectual: ¡Feliz cumpleaños!

Jorun Solheim, mag.art. 1970, Department of Social Anthropology, University of Oslo. Fue Profesora de Investigación en Género en la Universidad de Oslo, Investigadora principal en el AFI- Work Research Institute AFI, de Oslo, y es actualmente Investigadora Emérita del Instituto de Investigación Social de Oslo. Sus temas de interés han sido género, Trabajo y familia, estudios de unidades domésticas, cultura y modernidad. Publicó los libros Den åpne kroppen. Om kjønnssymbolikk i moderne kultur (El cuerpo abierto. Simbolismo de género en la cultura moderna), Oslo 1998; Den usynlige hånd. Kjønnsmakt og moderne arbeidsliv (La mano invisible. El poder generizado y la moderna vida del trabajo (modern working life), Oslo 2002; y Kjønn og modernitet (Género y modernidad), Oslo 2007. 